\title{
Testing the Stability of Beta: A Sectoral Analysis in Turkish Stock Market
}

\author{
Sibel Celik \\ Insurance and Risk Management Department, Dumlupinar University, Turkey \\ sibelcelik1@gmail.com
}

\begin{abstract}
The paper aims to test the stability of sector betas (systematic risk) in Turkish Stock Market for the period 03.01.2005-31.12.2009. We use rolling regression and recursive regression methods to test the stability of beta and two sub-samples to examine the impact of structural breaks on the beta behaviour, considering the 2007-2009 Global crisis. The findings support the instability of beta for most of the sectors and the results are robust when taking into account structural breaks. The paper is different from other studies in the Turkish literature because it uses different methodology, takes into account the crisis effect and focuses on the all sector betas.
\end{abstract}

Key Words: Systematic risk, beta, rolling regression, recursive regression

\section{Introduction}

The Capital Asset Pricing Model (CAPM) which was introduced independently by Treynor $(1961,1962)$, Sharpe (1964), Lintner(1965) and Mossin (1966) has been widely used in asset pricing and portfolio theory. CAPM measures the asset's sensitivity to systematic (non-diversifiable) risk which is represented by beta coefficient. The accurate estimation of beta is important for practitioners and academics. First, to estimate the beta (systematic risk) accurately helps investors to make their investment decisions easier. Second, the value of beta is also used by market participants to measure the performance of fund managers through Treynor ratio. Third, corporate financial managers used beta in capital structure decisions and investment appraisal (Choudhry and $\mathrm{Wu}, 2009$ ). Fourth, beta is used by academicians to test the market efficiency and asset pricing models. Beta parameter is estimated commonly as a constant parameter by using CAPM model through Ordinary Least Square (OLS) estimator. However the stability of beta is examined by numerous papers over the last decades (Blume, 1971; Alexander and Chervany, 1980;Bos and Newbold, 1984; Faff et al.,1992, Kok, 1994; Cheng, 1997; Moonis and Shah, 2002) and conclude that the beta is not constant over time.Since the OLS method estimates beta coefficient as a constant parameter, usage of OLS may give biased beta estimations. In the literature, different methods have been used to estimate time varying betas. Fama and Macbeth (1973) suggest to use rolling regression to estimate time varying betas. Groenewold and Fraser (1997) suggest to use rolling regression, recursive regression and Kalman filter technique to estimate time varying betas. These methods have also been used by various papers to estimate the time varying betas (Well, 1994; Moonis and Shah, 2002; Choudhry and $\mathrm{Wu}, 2007$; Nieto et al., 2011). In addition to these methods, different GARCH models (Bollerslev et al., 1988, Brooks et al., 1998; Yu, 2002) and Schwert and Seguin approach (Brooks et al., 2002) have been used to model time varying betas for different markets.

Time varying behaviour of sector betas have also been investigated for different countries by researchers in the literature (US: Gong et al., 2006; UK: Faff et al. (2000), Canada: He and Kryzanowski, 2008; Australia: Lie et al.2000; India, Moonish and Shah,2002; Greece: Volis et al., 2011). Similar with the evidence of other countries, the beta instability is also examined in Turkey by some papers.For example, Odabaşı (2000) tests the beta instability of common stocks traded in Istanbul Stock Exchange (ISE) for the period 1992-1997 and find that the stability of betas increases when the period is longer. Aygören and Saritas (2007) proposecorrection methods for beta estimation and conclude that the correction methods provide accurate beta estimations. Oran and Soytaş (2008) examine the characteristics and stability of individual stock and portfolio betas of stocks listed in ISE. They find significant relationship between market returns and both individual and portfolio returns, however these relationships are not stable. Altinsoy (2009) investigates the time varying behaviour of the betas of Turkish Real Estate Investment Trust sector by using Diagonal BEKK GARCH model, Schwert and Seguin model and the Kalman Filter and find that betas are not stable. Köseoğlu and Gökbulut (2011) test the stability of sector (services, financials and industrials) betas by using bivariate GARCH method in the ISE and conclude that sector betas are not constant supporting the existent literature. This paper aims to examine the beta behaviour of sector indices of ISE for the period 03.01.2005-31.12.2009 by using rolling regression and 
recursive regression methods. To examine the impact of structural breaks on the beta behaviour, we use two sub-samples considering the 2007-2009 Global crisis. The paper contributes to the existing literature in terms of presenting evidence of beta inconstancy in an emerging market sincethereis considerably less evidenceon beta instability in emergingmarkets. In addition, the paper is different from other studies in the Turkish literature because it uses different methodology, takes into account the crisis effect and focues on the all sector betas. The paper is organized as follows. Section 2 describes data and methodology. Section 3 explains the empirical results and section 4 concludes.

\section{Methodology}

We use daily closing prices of Istanbul Stock Exchange (ISE) sector indices and the ISE-30 All Share Index for the period between 03.01.2005-31.12.2009. Data on price indices are taken from Istanbul Stock Exchange. We calculate the return series as follows: $\ln \left(P_{t}\right) / \ln \left(P_{t-1}\right)$.We test the constancy of beta for two subsample considering 2007-2009 global crisis. In the literature, there are some papers using 17.07.2007 as a starting date of the global crisis (Dungey, 2009).Therefore, following Dungey (2009), we use 17.07.2007 as a starting date of the global crisis. Pre-crisis period comprises 03.01.2005-16.07.2007 and crisis period includes 17.07.2007-31.12.2009.Data was not dropped at any point except public holidays and weekends. The number of observation for pre-crisis and crisis period are 638 and 611, respectively. We apply rolling regression and recursive regression to estimate the time-varying beta of each sector indices. Indices of each sector are employed seperately. Therefore, we estimate rolling and recursive regression 48 times in total. Rolling regression is estimated using OLS and can be described as in Equation [1]. The window size is 60 and we get 578 and 551 daily beta for each sector indices.

$R_{i t}=\alpha_{t}+\beta_{t} R_{m t}+\delta_{t}$

$i=1,2 \ldots . . N$, denotes the sector indices,

[1]

$R_{i}=$ return on sector index $i$,

$R_{m}=$ return on the market portfolio

$t=\tau-59, \ldots \tau$,

$\tau=60, \ldots . . T$

Recursive regression is the another method used in estimation of time-varying beta. Similar with rolling regression, recursive regression is estimated using OLS, but differently, the sample size increase by one observation at any time. Recursive regression is defined as in Equation [2].

$R_{i t}=\alpha_{t}+\beta_{t} R_{m t}+\delta_{t}$

$i=1,2 \ldots . . N$, denotes the sector indices,

$R_{i}=$ return on sector index $i$,

$R_{m}=$ return on the market portfolio

$t=1 \ldots \tau$,

$\tau=T_{0} \ldots . T$

By estimating the Equation [2] for each sector index, we get 578 and 551 daily conditional beta series.

After estimating time-varying betas, we estimate Equation [3] to test the constancy of betas over time. If the slope coefficient, $\gamma_{2}$ is significant, we can conclude that beta values are not constant over time.

$\beta_{t}=\gamma_{1}+\gamma_{2} t+\varepsilon_{t}[3]$

\section{Results}

Descriptive Statistics: Table.1 shows the summary statistics of ISE all share index and the sector indices for the pre-crisis and crisis period. In Table.1, the mean returns are greater in pre-crisis than crisis period for most of the sector indices. Similar with mean returns, the standard deviations are higher in crisis periods. The skewness values indicate that the most of the index return series have negatively skewed distribution, however the negative skewness statistics are lower in crisis period than pre-crisis period in most indices. This finding is consistent with those of Alles and Kling (1994). Alles and Kling (1994) find that the negative skewness statistics decrease in down markets and increase in up markets. They explain this result with the risk attidude of investors. According to kurtosis statistics, it is clear that the the kurtosis values of index return series are greater than 3 and so series have fat-tails. In addition, JB statistics show that the index return series do not distribute normally. 
Table1: Descriptive Statistics

\begin{tabular}{|c|c|c|c|c|c|c|c|c|c|c|}
\hline & Mean & & Std Dev & & Skewness & & Kurtosis & & JB & \\
\hline & Pre-crisis & Crisis & Pre-crisis & Crisis & Pre-crisis & Crisis & Pre-crisis & Crisis & Pre-crisis & Crisis \\
\hline Banking & 0.0014 & 0.0002 & 0.0196 & 0.0299 & -0.1912 & 0.1996 & 3.6061 & 5.1888 & $13.63329 * * *$ & $125.8184^{* * *}$ \\
\hline Information & 0.0002 & 0.0002 & 0.0175 & 0.0220 & -0.7044 & -0.3820 & 6.1300 & 6.4577 & $312.6946^{* * *}$ & $318.7046^{* * *}$ \\
\hline Electric & 0.0000 & 0.0009 & 0.0210 & 0.0293 & -0.3721 & -0.3149 & 5.9938 & 7.4160 & $252.5839 * * *$ & $505.7383^{* * *}$ \\
\hline Financial Leasing & 0.0012 & -0.0005 & 0.0230 & 0.0284 & 0.4841 & -0.3627 & 7.8004 & 7.1872 & $636.4987^{* * *}$ & $459.0060^{* * *}$ \\
\hline Food & 0.0009 & 0.0003 & 0.0205 & 0.0216 & -0.4033 & -0.2153 & 7.2386 & 4.8708 & $494.1082^{* * *}$ & $93.66914^{* * *}$ \\
\hline Real Est. Inv. & 0.0005 & -0.0004 & 0.0180 & 0.0204 & -0.8221 & -0.5164 & 6.9295 & 5.4279 & $481.5755^{* * *}$ & $176.9395^{* * *}$ \\
\hline Holding & 0.0008 & -0.0005 & 0.0193 & 0.0249 & -0.3341 & -0.1410 & 3.9284 & 6.3492 & $34.73154^{* * *}$ & $287.1239^{* * *}$ \\
\hline Telecommunication & 0.0005 & 0.0002 & 0.0244 & 0.0261 & 0.1296 & -0.0710 & 4.1829 & 6.2393 & $38.92319 * * *$ & $267.2150^{* * *}$ \\
\hline Wood & 0.0007 & -0.0004 & 0.0195 & 0.0213 & -0.5813 & -0.3444 & 4.7281 & 6.0158 & $115.1405^{* * *}$ & $243.2253^{* * *}$ \\
\hline Metal & 0.0014 & -0.0002 & 0.0200 & 0.0296 & -0.2979 & 0.1511 & 5.1471 & 6.0294 & $131.7807^{* * *}$ & $241.7730^{* * *}$ \\
\hline Metalware and Machine & 0.0006 & -0.0003 & 0.0159 & 0.0222 & -0.5771 & -0.3099 & 5.3385 & 5.7213 & $180.5116^{* * *}$ & $197.9775^{* * *}$ \\
\hline Insurance & 0.0016 & -0.0003 & 0.0252 & 0.0267 & -0.2571 & -0.3437 & 4.5606 & 5.7316 & $71.65759 * * *$ & $201.6550^{* * *}$ \\
\hline Sport & 0.0009 & 0.0009 & 0.0152 & 0.0214 & 0.2182 & -1.7246 & 9.5168 & 26.4926 & $1132.234^{* * *}$ & $14329.83^{* * *}$ \\
\hline Stone & 0.0013 & -0.0003 & 0.0145 & 0.0152 & -0.8917 & -0.6932 & 6.5732 & 6.8121 & $423.3039 * * *$ & $418.2256^{* * *}$ \\
\hline Trade & 0.0013 & 0.0007 & 0.0158 & 0.0234 & -0.2205 & -0.1544 & 5.7995 & 11.1931 & $213.1738^{* * *}$ & $1708.574^{* * *}$ \\
\hline Textile & 0.0004 & 0.0001 & 0.0153 & 0.0187 & -1.5456 & -1.0015 & 8.8292 & 1.3767 & $1155.481^{* * *}$ & $588.8521^{* * *}$ \\
\hline Tourism & 0.0018 & -0.0009 & 0.0265 & 0.0275 & -0.6346 & -0.1588 & 6.1653 & 6.6198 & $308.6882^{* * *}$ & $335.5894^{* * *}$ \\
\hline Chemicals & 0.0013 & -0.0001 & 0.0180 & 0.0219 & -0.2235 & -0.3345 & 5.5234 & 6.4659 & $174.3024^{* * *}$ & $316.6878^{* * *}$ \\
\hline Service & 0.0010 & 0.0004 & 0.0151 & 0.0188 & -0.2473 & 0.0946 & 4.9679 & 5.4352 & $109.2816^{* * *}$ & $151.6336^{* * *}$ \\
\hline Transport & 0.0003 & 0.0015 & 0.0208 & 0.0275 & 0.0787 & -0.0188 & 5.7833 & 4.8524 & $206.2737^{* * *}$ & $87.25197^{* * *}$ \\
\hline Finance & 0.0012 & 0.0000 & 0.0187 & 0.0276 & -0.3069 & 0.1166 & 3.7258 & 5.5441 & $23.98583^{* * *}$ & $165.8901^{* * *}$ \\
\hline Industrial & 0.0010 & -0.0001 & 0.0144 & 0.0185 & -1.0196 & -0.3960 & 6.8875 & 6.1319 & $511.4845^{* * *}$ & $265.2571^{* * *}$ \\
\hline Technology & 0.0006 & 0.0004 & 0.0187 & 0.0211 & -0.7590 & -0.4234 & 5.9605 & 6.2538 & $293.7798^{* * *}$ & $287.2158^{* * *}$ \\
\hline Securities Investment & 0.0000 & 0.0001 & 0.0168 & 0.0194 & -1.0231 & -0.4738 & 7.5828 & 7.8299 & $668.5582^{* * *}$ & $615.7305^{* * *}$ \\
\hline ISE-all Share & 0.0011 & 0.0001 & 0.0160 & 0.0221 & -0.5575 & 0.0226 & 4.5670 & 5.8559 & $98.17049 * * *$ & $207.3580^{* * *}$ \\
\hline
\end{tabular}

Note: $^{* * *},{ }^{* *}$ and ${ }^{*}$ shows the $\% 1, \% 5$ and \%10 significance level. Pre-crisis period is from to 03.01.2005-16.07.2007 andcrisis period is from 17.07.2007 to 31.12.2009.

Stationary Tests: We test the stationary of variables by using ADF unit root test (Dickey and Fuller,1979). The results are given in Table 2. It is seen that the index return series are stationary in both pre-crisis and crisis period.

Table 2: ADF Unit Root Test Results

\begin{tabular}{|c|c|c|c|c|c|c|}
\hline & \multicolumn{3}{|l|}{ Pre-Crisis } & \multicolumn{3}{|l|}{ Crisis } \\
\hline & Test Statistic & Model & Lag & Test Statistic & Model & Lag \\
\hline Banking & $(-23.18471)^{* * *}$ & \# & 0 & $(-23.43130)^{* * *}$ & \# & 0 \\
\hline Information & $(-23.34922)^{* * *}$ & \# & 0 & $(-21.97105)^{* * *}$ & \# & 0 \\
\hline Electric & $(-22.29927)^{* * *}$ & \# & 0 & $(-18.19575)^{* * *}$ & \# & 1 \\
\hline Financial Leasing & $(-21.72556)^{* * *}$ & $\#$ & 0 & $(-22.31461)^{* * *}$ & $\#$ & 0 \\
\hline Food & $(-20.56261)^{* * *}$ & \# & 1 & $(-23.29736)^{* * *}$ & \# & 0 \\
\hline Real Est. Inv. & $(-22.09316)^{* * *}$ & \# & 0 & $(-21.55302)^{* * *}$ & \# & 0 \\
\hline Holding & $(-24.10622)^{* * *}$ & $\#$ & 0 & $(-21.50805)^{* * *}$ & $\#$ & 0 \\
\hline Telecommunication & $(-25.03938)^{* * *}$ & \# & 0 & $(-25.48784)^{* * *}$ & $\#$ & 0 \\
\hline Wood & $(-23.98348)^{* * *}$ & \# & 0 & $(-23.94035)^{* * *}$ & \# & 0 \\
\hline Metal & $(-24.54661)^{* * *}$ & \# & 0 & $(-21.45174)^{* * *}$ & \# & 0 \\
\hline Metalware and Machine & $(-23.94495)^{* * *}$ & \# & 0 & $(-20.86109)^{* * *}$ & \# & 0 \\
\hline Insurance & $(-22.87951)^{* * *}$ & $\#$ & 0 & $(-21.39955)^{* * *}$ & \# & 0 \\
\hline Sport & $(-23.29143)^{* * *}$ & \# & 0 & $(-13.40086)^{* * *}$ & \# & 2 \\
\hline Stone & $(-21.80679)^{* * *}$ & $\#$ & 0 & $(-21.82071)^{* * *}$ & \# & 0 \\
\hline Trade & $(-25.03185)^{* * *}$ & \# & 0 & $(-23.71992)^{* * *}$ & \# & 0 \\
\hline Textile & $(-22.72843)^{* * *}$ & \# & 0 & $(-22.61243)^{* * *}$ & \# & 0 \\
\hline Tourism & $(-24.04567)^{* * *}$ & \# & 0 & $(-22.54734)^{* * *}$ & $\#$ & 0 \\
\hline Chemicals & $(-24.69716)^{* * *}$ & $\#$ & 0 & $(-22.07206)^{* * *}$ & \# & 0 \\
\hline Service & $(-24.60458)^{* * *}$ & \# & 0 & $(-24.36001)^{* * *}$ & \# & 0 \\
\hline Transport & $(-24.87301)^{* * *}$ & $\#$ & 0 & $(-20.78828)^{* * *}$ & $\#$ & 0 \\
\hline Finance & $(-23.28972)^{* * *}$ & $\#$ & 0 & $(-22.98088)^{* * *}$ & $\#$ & 0 \\
\hline Industrial & $(-23.57021)^{* * *}$ & \# & 0 & $(-21.45706)^{* * *}$ & $\#$ & 0 \\
\hline Technology & $(-23.16052)^{* * *}$ & \# & 0 & $(-22.27723)^{* * *}$ & \# & 0 \\
\hline
\end{tabular}




\begin{tabular}{llllcll} 
Securities Investment & $(-22.51245)^{* * *}$ & $\#$ & 0 & $(-23.79433)^{* * *}$ & $\#$ & 0 \\
ISE-all Share & $(-23.52029)^{* * *}$ & $\#$ & 0 & $(-22.95402)^{* * *}$ & $\#$ & 0 \\
\hline
\end{tabular}

For \%1 and \%5 significance level Mac Kinnon critical values are -3.45 and -2.87 (with intercept) respectively. *** represents \%1 significance level. \# represents "with intercept model".

Rolling Regression and Recursive Regression: Before the results of regression analysis, we plot the time varying betas of rolling and recursive regressions (Equation [1] and Equation [2] ) for pre-crisis and crisis period in Figure 1and Figure 2, respectively. For brevity, we only report the graphs of the banking sector, information sector indices for pre-crisis and crisis period.

Figure1: Rolling and recursive betas for banking sector and information sector index in pre-crisis periods respectively.

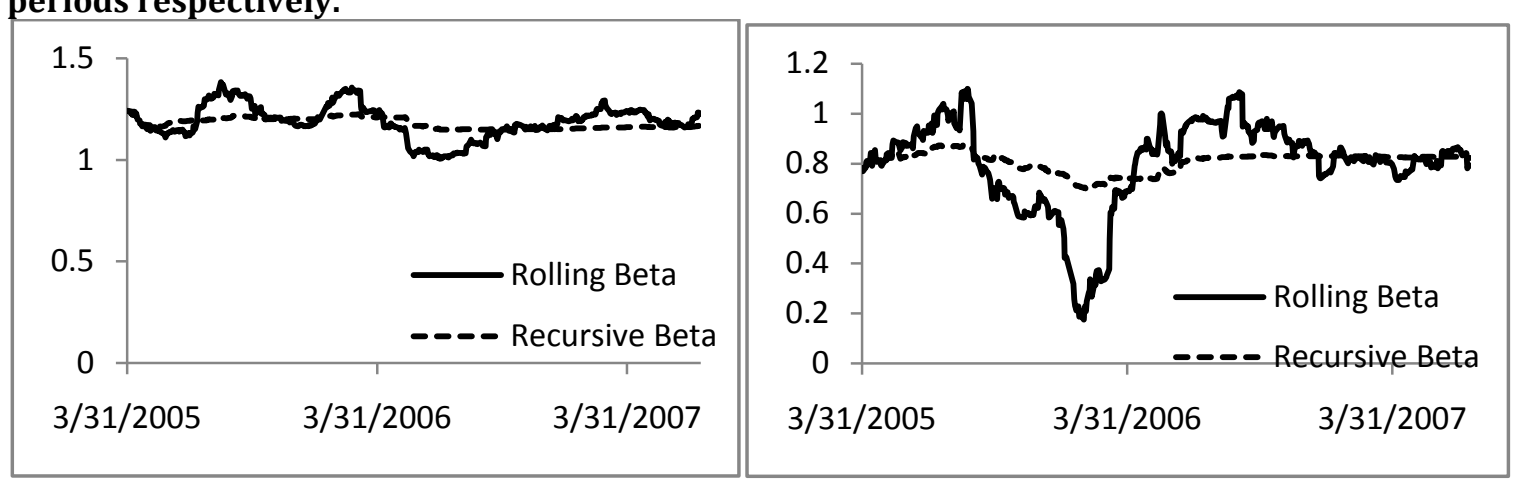

Figure 2: Rolling and recursive betas for banking sector and information sector index in crisis periods, respectively.

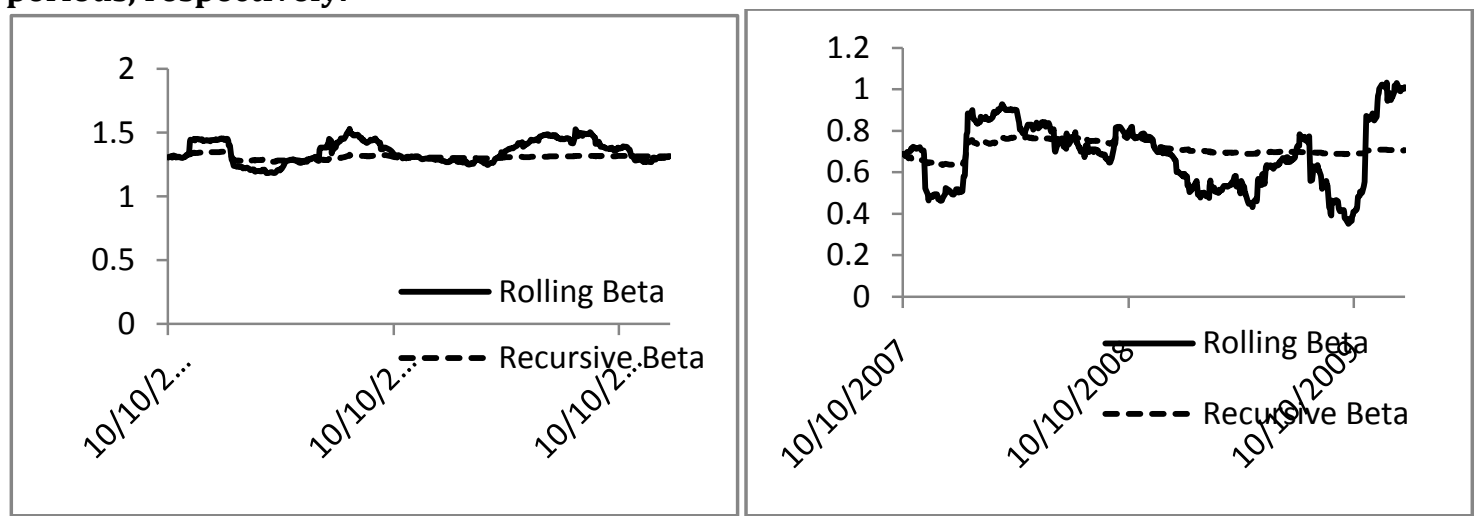

It is clear in Figure.1 and Figure. 2 that beta is not constant both in pre-crisis and crisis period and rolling betas shows more variation than the recursive betas over time. This result is expected because the nature of the rolling and recursive regressions. Rolling regression gives equal weight to each observation in the rolling window (60 days), however in recursive regression each successive observation carries less weight (Yeo,2001). After analysing the betas over time through graphs, we test the constancy of betas by using more formal method. We regress rolling and recursive betas on a time- trend to test whether beta values change over time (Equation [3]). The findings are given in Table.3

Table 3:Time Series Properties of Rolling and Recursive Betas

\begin{tabular}{lllll}
\hline Sector & Rolling Beta & \multicolumn{2}{l}{ Recursive Beta } \\
\hline Banking & Pre-crisis & Crisis period & Pre-crisis & \multicolumn{1}{l}{ Crisis period } \\
Information & $-0.0001^{* *}(-2.0805)$ & $0.0001^{* *}(2.0550)$ & $-0.0001^{* * *}(-10.1963)$ & $0.00001(1.1231)$ \\
Electric & $0.0001^{*}(1.6959)$ & $-0.0001(-1.1744)$ & $0.00003^{* *}(1.9384)$ & $-0.00004(-1.4209)$ \\
Financial Leasing & $-0.00003(-0.2859)$ & $-0.0003^{* * *}(-2.7703)$ & $-0.0001^{* * *}(-6.7496)$ & $-0.0003^{* * *}(16.8581)$ \\
Food & $-0.0003^{* * *}(-4.1055)$ & $-0.0011^{* * *}(-5.7799)$ & $-0.0003^{* * *}(-16.0920)$ & $-0.0002^{* * *}(-3.5256)$ \\
Real Est. Inv. & $-0.0002^{* * *}(-2.2233)$ & $-0.0004^{* * *}(-9.8277)$ & $0.0001^{* * *}(2.3400)$ & $-0.0002^{* * *}(-20.8731)$ \\
Holding & $-0.0001(-0.9084)$ & $0.00004(-0.4143)$ & $-0.0001^{* * *}(-5.6954)$ & $-0.0002^{* * *}(-13.2736)$ \\
\hline
\end{tabular}




\begin{tabular}{|c|c|c|c|c|}
\hline Telecommunication & $-0.0003^{* * *}(-3.3750)$ & $-0.0008^{* * *}(8.3037)$ & $0.0000(0.7055)$ & $-0.0002^{* * *}(-6.7285)$ \\
\hline Wood & $0.0002^{* * *}(2.5947)$ & $-0.0002^{* * *}(-3.0104)$ & $0.0001^{* * *}(2.4859)$ & $-0.0001^{* * *}(-15.8365)$ \\
\hline Metal & $0.00001(0.1627)$ & $0.0003^{* * *}(4.5519)$ & $0.0000(0.4709)$ & $0.0003^{* * *}(19.2428)$ \\
\hline Metalware and Machine & $0.0001^{* *}(2.2981)$ & $0.0001^{* *}(2.3406)$ & $-0.0000(-1.4132)$ & $0.0002^{* * *}(20.1293)$ \\
\hline Insurance & $0.0003^{* * *}(4.0355)$ & $0.00004 \quad(-0.4283)$ & $0.0001^{* * *}(5.9473)$ & $0.0003^{* * *}(11.5024)$ \\
\hline Sport & $-0.0006^{* * *}(-8.4564)$ & $0.0006^{* * *}(5.9756)$ & $-0.0003^{* * *}(-16.7097)$ & $0.0004^{* * *}(14.6920)$ \\
\hline Stone & $-0.0001^{* * *}(-2.7119)$ & $0.00004(-0.7621)$ & $0.00004^{* * *}(3.4080)$ & $0.0001^{* * *}(4.2318)$ \\
\hline Trade & $-0.0002^{* * *}(-5.0681)$ & $0.0002^{* * *}(2.6910)$ & $-0.0002^{* * *}(-15.3321)$ & $-0.000004(-0.1978)$ \\
\hline Textile & $0.0001(1.5345)$ & $-0.0006^{* * *}(5.6572)$ & $0.0000(0.4196)$ & $-0.0001^{* * *}(-7.8647)$ \\
\hline Tourism & $0.0002^{* *}(2.2946)$ & $-0.0007 * * *(4.3393)$ & $0.0004^{* * *}(13.3538)$ & $-0.0004^{* * *}(-13.7172)$ \\
\hline Chemicals & $0.0001^{* *}(1.9507)$ & $-0.0002^{* * *}(3.2940)$ & $0.0001^{* * *}(2.7684)$ & $0.0001^{* * *}(7.2900)$ \\
\hline Service & $-0.0003^{* * *}(-8.0859)$ & $-0.0002 * * *(3.5736)$ & $-0.0001^{* * *}(-14.7397)$ & $-0.0001^{* * *}(-4.3637)$ \\
\hline Transport & $-0.0007^{* * *}(-5.9399)$ & $-0.0005^{* * *}(3.9005)$ & $-0.0004^{* * *}(-19.0622)$ & $0.00001(0.5949)$ \\
\hline Finance & $0.0001^{* * *}(3.4527)$ & $0.0001^{* * *}(2.7658)$ & $-0.0000(-0.6221)$ & $0.00005^{* * *}(6.5329)$ \\
\hline Industrial & $-0.0000(-0.1143)$ & $-0.0001^{* * *}(2.6726)$ & $0.00003^{* * *}(3.4740)$ & $0.0001^{* * *}(7.1190)$ \\
\hline Technology & $0.0003^{* * *}(6.8348)$ & $-0.0001(-1.0233)$ & $0.0003^{* * *}(18.6152)$ & $0.0001^{* * *}(2.7205)$ \\
\hline Securities Investment & $-0.0001^{* * *}(2.3837)$ & $-0.0001(-1.5867)$ & $-0.0002^{* * *}(-9.4180)$ & $-0.00004^{* * *}(2.8064)$ \\
\hline Number of Sig.Coef. & $19 \quad 17$ & 19 & 20 & \\
\hline
\end{tabular}

Both in rolling and recursive regressions, the coefficient of time-trend is significant in the most sectors in pre-crisis and crisis periods supporting the beta is not constant over time. In pre-crisis period 13 and 11 of the beta values decrease for rolling and recursive regreesion respectively. In crisis period, 14 and 12 of the beta values decrease over time for rolling and recursive regression, respectively. The number of significant coefficient is 19 in pre-crisis period and 17 and 20 for rolling and recursive regression in crisis period respectively.

\section{Conclusion}

The paper aims to examine the time series properties of the systematic risk measure in Istanbul Stock Exchange sector indices by using rolling and recursive regression analysis. The results show that estimated beta values by rolling and recursive regressions are not constant over time. The findings are robust when we consider the structural break (2007-2009 global crisis). Our findings support those of Oran and Soytaş (2008), Altınsoy (2009), Köseoğlu and Gökbulut (2011) in Turkish stock market.The instability of beta requires time-varying assumption on systematic risk to estimatethe systematic risk accurately.Investors should also consider the time-varying behaviour of beta in the investment decision and portfolio management.Since beta is not constant over time, OLS estimation of beta may overestimate or underestimate of true value of beta. Thus, investor should estimate time varying beta rather than constant beta for their investment decision.

\section{References}

Alles, L. \& John, K. (1994). Regularities in the Variation of Skewness in Stock Index Returns. Journal of Financial Research, 17(3), 427-438.

Altınsoy, G. (2009). Time Varying Beta Estimation For Turkish Real Estate Investment Trusts: An Analysis of Alternative Modelling Techniques, A Thesis for the degree of Master of Science, Middle East Technical University.

Alexander, G. J. \& Norman, L. C. (1980). On the estimation and stability ofBeta. The Journal of Financial and Quantitative Analysis, 15(1), 123-137.

Aygören, H. \& Saritas, H. (2007). Is a correction necessary for beta estimation?Akdeniz I.I.B.F. Journal Antalya, 7(14), 110-121.

Blume, M. (1971). On the assessment of risk. The Journal of Finance, 26(1), 1-10.

Bos, T. \& Newbold, P. (1984). An Empirical Investigation of the Possibility of Systematic Stochastic Risk in the Market Model. Journal of Business, 57(1), 35-41. 
Bollerslev, T., Engle, R. F. \& Wooldridge, J. M. (1988). A Capital Asset Pricing Model with Time-Varying Covariances. The Journal of Political Economy, 96(1), 116-131.

Brooks, R. D., Faff, R. W. \& McKenzie, M. D. (1998). Time-Varying Beta Risk of Australian Industry Portfolios: A Comparison of Modelling Techniques. Australian Journal of Management, 23(1), 122.

Brooks, R. D., Faff, R. W. \& McKenzie, M. (2002). Time-varying country risk: An assessment of alternative modelling techniques. The European Journal of Finance, 8(3), 249-274.

Cheng J. W. (1997). A switching regression approach to the stationarity of systematic and non-systematic risks: the Hong Kong experience. Applied Financial Economics, 7, 45-57.

Choudhry, T. \& Wu, H. (2007). Time-Varying Beta And Forecasting UK Company Stock Returns: Garch Models vs Kalman Filter Method, University of Southampton Press, Southampton.

Choudhry, T. \& Wu, H. (2009). Forecasting the Weekly Time Varying Beta of UK Firms: GARCH models vs Kalman Filter Method. European Journal of Finance, 15(3-4), 437-444.

Dickey, D. A. \& Fuller, W. A. (1979). Distribution of the estimators for autoregressive time series with a unit root. Journal of the American Statistical Association, 74, 427-431.

Faff, R. W., Lee, J. H. \& Fry, T. R. L. (1992). Time stationarity of systematic risk: Some Australian evidence. Journal of Business Finance and Accounting, 19(2), 253-270.

Faff, R. W., Hiller, D. \& Hiller, J. (2000). Time varying beta risk: an analysis of alternative modelling techniques. Journal of Business Finance and Accounting, 27(5-6), 523-55

Fama, E. \& Macbeth, J. (1973). Risk, return and equilibrium: Empirical tests. Journal ofPolitical Economy, 81(3), 607-636.

Gong, S. X. H., Michael, F. \& Cullinane, K. (2006). Beta estimation and stability in the US-listed international transportation industry. Review of Pacific Basin Financial Markets and Policies, 9 (3), 463-90.

Groenewold, N. \& Fraser, P. (1999). Time-varying estimates of CAPM betas. Mathemathics and Computers in Simulation, 48, 531-539.

He, Z. \& Kryzanowski, L. (2008). Dynamic betas for Canadian sector portfolios. International Review of Financial Analysis, Elsevier, 17(5), 1110-1122

Kok, K. L. (1994). Beta forecasts of Malaysian securities. Malaysian Management Review, 29, 14-21.

Köseoğlu, S. D. \& Gökbulut, R. İ. (2011). Market Risk of Turkish Sectors Between 2001 and 2011: A Bivariate GARCH Approach. African Journal of Business Management, 6(23), 6948-6957.

Lie, F., Brooks, R. \& Faff, R. (2000). Modelling the Equity Beta Risk of AustrallianFinancial Sector Companies. Australian Economic Papers, 39, 301-311.

Lintner, J. (1965). The valuation of risk assets and the selection of risky investments in stock portfolios and capital budgets. Review of Economics and Statistics, 47(1), 13-37.

Moonis, S. A. \& Shah, A. (2002). Testing for time variation in beta in India. Journal of Emerging Markets and Finance, 2(2), 163-180.

Mossin, J. (1966). Equilibrium in a Capital Asset Market. Econometrica, 34(4), 768-783.

Nieto, B., Orbe, S. \& Zarraga, A. (2011).Time- Varying Beta Estimators in the Mexican Emerging Market, Universidad del Pais Vasco, https://addi.ehu.es/handle/10810/5283

Odabaşı, A. (2000). Evidence on the stationarity of beta coefficients: the case of Turkey. Working Paper. Bogazici University. Istanbul

Oran, A. \& Soytaş, U. (2008). Stability in the ISE: Betas for Stocks and Portfolios, MARC Working Paper Series, Working Paper No.2008-03.

Sharpe, W. F. (1964). Capital asset prices: A theory of market equilibrium under conditions of risk. Journal of Finance, 19(3), 425-442.

Treynor, J. L. (1961). Market Value, Time, and Risk. Unpublished manuscript.

Treynor, J. L. (1962). Toward a Theory of Market Value of Risky Assets. Unpublished manuscript. A final version was published in 1999, in Asset Pricing and Portfolio Performance: Models, Strategy and Performance Metrics. Robert A. Korajczyk (editor) London: Risk Books, pp. 15-22.

Volis, A., Diamandis, P. \& Karathanassis, G. (2011). Time Varying beta risk fort he stocks of the Athens Stock Exchange: a multivariate approach. Investment Management and Financial Innovations, 8(1), 191-198.

Well, C. (1994). Variable Betas on the Stockholm Exchange 1971-1989. Applied Economics, 4, 75-92.

Yeo, J. (2001). Modelling Time-Varying Systematic Risk in Australia, International Congress on Modelling \& Simulation, Western Australia. Modelling \& Simulation Society of Australia \& New Zealand Inc, 3, 1565-1570.

Yu, J. (2002). Forecasting Volatility in the New Zealand Stock Market. Applied Financial Economics, 12, 193-202. 